\title{
Compliance penal y su función en la atribución de responsabilidad penal / administrativa de las personas jurídicas
}

Percy André Sota Sánchez

Magíster en Ciencias Penales por la Universidad de San Martín de Porres. Especialista en Compliance por AENOR España y por la Universidad del Pacífico. Miembro de la Asociación Iberoamericana de Derecho Penal Económico y de la Empresa. Miembro investigador del Centro de Estudios en Derecho penal económico y de la empresa-CEDPE.

SUMARIO:

I. ¿Qué es el Compliance en Materia Penal?

1. Origen y evolución del Compliance Penal.

2. Naturaleza jurídico-empresarial del Compliance.

2.1. Aproximación a su naturaleza: Compliance y sus relaciones con Fenómenos Empresariales conexos.

2.2. El Compliance como forma de Autorregulación: ¿pura, regulada o metaregulación?

3. Aproximación al concepto de Compliance Penal.

II. ¿Para qué sirve el Compliance Penal?

1. Funciones del Compliance penal.

1.1. Función de prevención de Delitos.

1.2. Función de confirmación de la Normativa Penal.

1.3. Función de coadyuvar en la formación de una cultura de cumplimiento, pero en el ámbito Penal.

2. El Compliance Penal en la imputación de Responsabilidad Penal/ Administrativa de las Personas Jurídicas.

2.1. Sistemas de imputación de Responsabilidad Penal de las Personas Jurídicas: Derecho comparado, Doctrina y Jurisprudencia.

2.2. Ubicación del Compliance Penal en la atribución de Responsabilidad Penal/Administrativa de las Personas Jurídicas.

* El artículo fue recibido con fecha 08-07-18. 


\section{RESUMEN:}

En el presente artículo el autor realiza un análisis de la naturaleza del Compliance, llegando a formular un concepto a partir de su relación con otros fenómenos empresariales. Luego de ello, enlaza el Compliance con la responsabilidad penal y administrativa de las personas jurídicas, realizando un análisis de las legislaciones del Perú, Chile, España e Italia, asignándole tres funciones: prevención de delitos, confirmación de la norma penal y formación de una cultura de cumplimiento en el ámbito penal.

Palabras clave: responsabilidad penal, responsabilidad administrativa, personas jurídicas, Compliance, autorregulación, autorresponsabilidad, gobierno corporativo, responsabilidad social, ética empresarial, ciudadanía corporativa.

\footnotetext{
ABSTRACT:

In this article, the author analyzes the nature of Compliance, achieving to formulate a concept based on its relationship with other business phenomena. Thereafter, he links Compliance with criminal and administrative responsibility of legal entities, analyzing the legislation of Peru, Chile, Spain and Italy, assigning them three functions: crime prevention, confirmation of the criminal law and formation of a compliance culture in the criminal law field.

Keywords: criminal responsibility, administrative responsibility, legal entities, Compliance, self-regulation, self-responsibility, corporate governance, social responsibility, business ethics, corporate citizenship.
}

\section{I. ¿QUÉ ES EL COMPLIANCE EN MATERIA PENAL?}

\section{Origen y evolución del Compliance penal.}

En la literatura jurídica diversos autores tratan de identificar cuál es el origen del Compliance', siendo común encontrar referencias a que el origen del Compliance se haya en el Derecho de los Estados Unidos de América y, en concreto, en el Derecho del mercado de valores y de la competencia; es decir, en ámbitos ajenos al Derecho penal.

En el Derecho del mercado de valores, gracias al impulso de la Comisión de Valores de los Estados Unidos de América-US. Securities and Exchange Comission, el Compliance aparece como una forma de autorregulación en las empresas. Su aparición se remonta a la década de 1930, cuando con el fin de evitar abusos de información privilegiada se comenzó a exigir a las empresas que adopten controles internos. Posteriormente, en el año 2002 se emitió la
Sarbanes Oxley Act —-también conocida como Ley de reforma de la contabilidad pública de empresas y protección al inversionista-, en la cual, aún se sigue un modelo de autorregulación en las empresas, aunque más limitado, pues esta ley obliga a las empresas a adoptar medidas de organización interna y canales de denuncia anónimos².

Otro sector del Derecho de los Estados Unidos de América donde también se suele identificar el origen del Compliance es en el ámbito del Derecho de la competencia. Así, por ejemplo, Nieto Martín sostiene que a partir de la mitad de los años 40 algunas empresas, fabricantes de componentes eléctricos, se dotan de programas de cumplimiento para la prevención de conductas contrarias a la competencia. En esos años, el Departamento de Justicia - Department of Justice USA - descubre un importante cartel en ese sector y exige a las empresas que se doten de programas de cumplimiento. El derecho de la competencia fue, por lo tanto, uno de los orígenes de los pro-

1. Por todos, Vid. NIETO MARTíN, Adán: El cumplimiento normativo, en Nieto Martín, Adán [Dir.], Manual de cumplimiento penal en la empresa. Valencia: Tirant lo Blanch, 2015, pp. 27-31.

2. Ibíd., pp. $27-28$. 
gramas de cumplimiento. De hecho, a finales de los años 80 se le consideraba aún el sector donde las estrategias de cumplimiento se encontraban más avanzadas ${ }^{3}$.

Sin embargo, es a raíz de la Foreing Corrupt Practices Act —en adelante, "FCPA" o Ley de prácticas corruptas-, que los programas de cumplimiento alcanzan un desarrollo notable, sobre todo en materia penal, enfocados básicamente en el ámbito de la prevención de la corrupción. A partir de esta Ley y de los nuevos enfoques de lucha contra la corrupción desde el Compliance penal, es que en la doctrina penal se ha denominado a este nuevo fenómeno como "privatización de la lucha contra la corrupción"4.

Esta Ley, como las anteriores que tuvieron su origen en escándalos públicos o épocas de crisis, tuvo su origen a raíz del escándalo político del "Watergate". La FCPA fue promulgada por el Congreso de Estados Unidos y refrendada por el ex presidente Jimmy Carter el 19 de diciembre de 1977 y constituyó, primigeniamente, un cuerpo legislativo orientado solo a prohibir la corrupción de funcionarios públicos extranjeros. Esta Ley fue objeto de modificaciones a través de la Omnibus trade and competitiveness Act de 1988 - que es una Ley que básicamente regula reglas de competitividad y comercio-, que modificó la FCPA en relación a la definición de "pagos permitidos", en la variación de los requisitos del tipo subjetivo $y$, finalmente, en el endurecimiento de las consecuencias jurídicas de esta ley; $y$, por la International Antibribery and Fair Competition Act de 1998, que amplía el concepto de destinatarios de esta Ley, que ya no solo incluye a las empresas listadas en la Bolsa de Valores y a las personas o empresas norteamericanas que desarrollen su actividad económica en dicho territorio - originalmente se excluían a las sucursales extranjeras-, sino que ahora también incluye a las personas naturales o jurídicas, ya sean extranjeras o norteamericanas, cuyo acto de corrupción tenga algún tipo de relación con el espacio estadounidense ${ }^{5}$.

En resumen, y para los efectos que aquí nos interesan, la FCPA establece la obligación de las empresas de adoptar medidas de control internas - programas de cumplimiento- para prevenir la corrupción. Como bien sostiene Nieto Martín, desde entonces y sobre todo a partir de los años 90, los programas de cumplimiento se han convertido en una de las piezas claves en la lucha contra la corrupción ${ }^{6}$.

La última gran reforma en el Derecho de los Estados Unidos de América que influye directamente en la evolución del Compliance, tiene que ver con la Dodd-Frank Wall Street Reform and Consumer Protection Act del año 2010, que fue introducida a consecuencia de la recesión económica y crisis financiera que afectó a dicho país durante los últimos años, e introduce cambios significativos en la regulación financiera, mercantil y cambiaria de dicho país en el ámbito del gobierno corporativo, de las prácticas de compensación económica y crea nuevas agencias gubernamentales, como el Consejo de Supervisión de la Estabilidad Financiera y la Oficina de Protección al Consumidor Financiero.

En lo que a nuestra materia corresponde, Gon-

3. Ibíd., p. 27.

4. Por todos, Vid. NIETO MARTÍN, Adán. La privatización de la lucha contra la corrupción. ARROYO ZAPATERO, Luis; NIETO MARTÍN y ADÁN [Directores]. El Derecho penal en la era Compliance. Tirant lo Blanch. Valencia: 2013, pp. 191-210.

5. Para mayor detalle, Vid. CARRIÓN ZENTENO, Andy. Criminal Compliance. De la Ley de EE. UU de Prácticas Corruptas en el Extranjero, el riesgo de las empresas de acción internacional y la transcendencia de los programas de cumplimiento.

6. NIETO MARTíN, Adán: El cumplimiento normativo, en Nieto Martín, Adán [Dir.], Manual de cumplimiento penal en la empresa. Valencia: Tirant lo Blanch, 2015, p. 28. 
záles de León Berini explica que esta nueva Ley introduce un sistema avanzado de prevención - programa de cumplimiento-, al crearse un consejo para identificar y abordar los riesgos más sistémicos planteados por las entidades financieras grandes y complejas y también por parte de los productos financieros de riesgo novedosos, antes de que puedan llegar a amenazar realmente la estabilidad de la economía americana?.

La importancia de la FCPA es sumamente relevante para la prevención y lucha contra la corrupción. El ex Fiscal General Interino de la División de lo Penal del Departamento de Justicia de los Estados Unidos de América, Kenneth A. Blanco, señaló con motivo del $40^{\circ}$ Aniversario de la FCPA y el $20^{\circ}$ Aniversario de la Convención Antisoborno de la Organización para la Cooperación y el Desarrollo Económicos que solo en el año 2016 el Departamento de Justicia de los Estados Unidos presentó más de 35 casos penales contra individuos y 17 casos contra empresas por cargos penales de "sobornos" en el extranjero. Esto dio como resultado una recaudación de más de US\$ 1.6 mil millones en multas, sanciones y devolución ${ }^{8}$.

\section{Naturaleza jurídico-empresarial del Compliance.}

\subsection{Aproximación a su naturaleza: Compliance y sus relaciones con fenómenos empresariales conexos.}

¿Cuál es la naturaleza del Compliance? ¿Es jurí- dica o se corresponde con una herramienta de gestión empresarial? Para poder dar respuesta a estas peguntas es importante analizar este concepto con aquellos fenómenos conexos propios de la actividad empresarial, como lo son el Gobierno Corporativo, la Ética Empresarial y la Responsabilidad Social Corporativa.

El Gobierno Corporativo comprende aquel sistema donde se regulan las formas en que se deben dar las relaciones entre los diversos actores en el interior de la empresa; es decir, entre los accionistas, gerentes, administradores y representantes, así como las relaciones entre éstos con los trabajadores y acreedores.

El Buen Gobierno Corporativo es un asunto de especial atención por la Organización para la Cooperación y Desarrollo Económico-OCDE. Incluso, en el año 2004 se elaboraron los Principios de Gobierno Corporativo de la OCDE $; y$, en el año 2015, se elaboraron los Principios de Gobierno Corporativo del G20 y de la OCDE ${ }^{10}$.

El hecho que las empresas se estructuren y desarrollen sus actividades aplicando los Principios del Buen Gobierno Corporativo — soft law - es fundamental para la transparencia y correcto funcionamiento del mercado. A través de estos principios se busca un sistema de balances en la empresa, cuyo fin es proteger a los socios - shareholder - y a las personas que se pueden ver afectadas por sus actividades sociales - stakeholder-.

Existen tres aspectos en los que se relacionan

7. GONZÁLES DE LEÓN BERINI, Arturo. El criminal Compliance en la reforma norteamericana de la Dodd-Frank Act. SILVA SÁNCHEZ, Jesús María [Dir.]. Criminalidad de empresa y Compliance. Prevención y reacciones corporativas. Barcelona: Atalier, 2013, p. 134.

8. BLANCO, Kenneth A. "Delivers remarks at FCPA/OECD Anniversary Conference", organized by DOJ, OECD, and SEC, November 9, 2017. Disponible en: <https://wp.nyu.edu/compliance enforcement/2017/11/10/acting-assistant-attorney-general-kenneth-blanco-keynote-address-on-fcpa-and-anti-bribery-convention/>.

9. Se pueden visualizar estos principios en: <https://www.oecd.org/daf/ca/corporategovernanceprinciples/37191543.pdf>.

10. Se pueden visualizar estos principios en: <http://www.keepeek.com/Digital-Asset-Management/oecd/governance/g20-ocde-principios-de-gobierno-corporativo 9789264259171-es\#page5>. 
el Buen Gobierno Corporativo y el Compliance. El primero es el cumplimiento de la legalidad, ello debido a que actualmente todos los códigos de buen gobierno corporativo exigen al Consejo que vele para que en sus relaciones con los grupos de interés la empresa respete las leyes y los reglamentos, cumpla de buena fe sus obligaciones y contratos, respete los usos de buenas prácticas de los sectores y territorios donde ejerza su actividad y observe aquellos principios adicionales de responsabilidad social que hubiere aceptado voluntariamente.

El segundo se da en la política de gestión de riesgos, ya que los códigos de buen gobierno consideran que una de las facultades indelegables del Consejo es aprobar la política de gestión de riesgos, así como el seguimiento periódico de los sistemas internos de información y control. El tercero es la prevención de una clase de delitos: los delitos societarios, toda vez que una parte esencial de los códigos de buen gobierno son las relativas a las retribuciones de los consejeros o a la evitación de conflictos de intereses, lo que ayuda a la prevención de delitos como el de administración desleal. También son numerosas las disposiciones tendentes a aumentar la transparencia en la gestión y, por tanto, la calidad y la fiabilidad de la información societaria. Dada la comunidad de intereses y objetivos es natural que entre los encargados de cumplimiento normativo y los de Buen Gobierno exista una estrecha relación, cuando no confusión, institucional"1.

La relación entre Compliance y Ética Empresarial o corporativa se ve reflejada en el modelo de Compliance que adopte la empresa. Así podemos observar dos modelos claramente definidos: un modelo orientado a la vigilancia y el cumplimiento de la legalidad; $y$, un modelo orientado a la promoción de valores éticos en la entidad y el cumplimiento de la legalidad.

Cumplimiento normativo y ética son, lógicamente, fenómenos conexos y con amplias zonas de intersección. Aunque es posible diseñar un programa de cumplimiento, basado en la vigilancia y en el control, por pura coherencia; tenemos que en una empresa que parta de una visión amplia de la Responsabilidad Social Corporativa y que asuma la Ética, las medidas de cumplimiento deben partir necesariamente de la promoción de valores éticos. La falta de coherencia entre el programa de cumplimiento y los valores éticos básicos tiene consecuencias perjudiciales para ambos subsistemas. Así, por ejemplo, no tiene sentido imponer sanciones disciplinarias desproporcionadas o imponerlas mediante un procedimiento que desconoce los principios elementales del proceso justo. Un sistema de cumplimiento basado en valores éticos es más legítimo y, por tanto, más eficaz ${ }^{12}$.

La Responsabilidad Social Corporativa o Empresarial es la forma en que las empresas se responsabilizan y prevén sus acciones frente a los impactos que sus decisiones y actividades ocasionan en la sociedad y en el medio ambiente -ISO 26000: Guía sobre responsabilidad social-. Estas acciones no son filantrópicas, sino que deben estar dentro del concepto de alineación con el negocio. Esto genera un cambio en el paradigma económico de la organización empresarial. Así, mientras que el ex Premio Nobel de Economía del año 1976, Milton Friedman, sostuvo en el año 1962 la Teoría del Accionista - Stockholder Theory ${ }^{13}$ — en el sentido que el negocio de las empresas es generar valor económico para los accionistas, o, en otras palabras, la única responsabilidad de una empresa es aumentar sus beneficios; actualmente se

11. Al respecto, Vid. NIETO MARTíN, Adán. El cumplimiento normativo. Manual de Cumplimiento Penal en la Empresa. NIETO MARTíN, Adán [Dir.]. Valencia: Tirant Lo Blanch, 2015, pp. 38-39.

12. Ibíd., p. 44.

13. Para mayores referencias, Vid. FRIEDMAN, Milton. Capitalism and Freedom. Chicago: University of Chicago, 1962 p. 133 y ss. 
viene sosteniendo en esta manera la doctrina del valor compartido, de Michael Porter ${ }^{14}$, en el sentido que el propósito de la empresa debe ser redefinido como creación de valor compartido. Esto impulsará la siguiente ola de innovación y crecimiento de la productividad en la economía global. En resumen, la Responsabilidad Social Corporativa conlleva a una nueva visión de la empresa, como ciudadano responsable - good citizens corporations-, como un actor no solo económico, sino social y político, con obligaciones hacia su comunidad ${ }^{15}$.

Las relaciones entre Compliance y Responsabilidad Social Corporativa dependen lógicamente de cómo se entienda en cada empresa y en qué extensión tengan sus contenidos. Si se entiende como mecenazgo y sostenibilidad, sus conexiones son menores; si en cambio se fundamenta en la idea de good citizens corporations y asume la promoción de determinados valores éticos, el respeto a la legalidad — por ejemplo, a través de programas de cumplimiento-, a los derechos humanos y la lucha contra la corrupción, deben considerarse parte del mismo objetivo ${ }^{16}$.

\subsection{El Compliance como forma de autorregulación: ¿pura, regulada o metaregulación?}

La globalización económica, los altos niveles de tecnificación de las actividades de producción y distribución, el constante desarrollo tecnológico, la profesionalización y especialización en la industria, el crecimiento de las empresas, su in- ternacionalización y su organización compleja, entre otros factores relacionados a la actividad empresarial moderna de la sociedad postindustrial, conllevan a una crisis en la capacidad del Estado en intervenir adecuadamente en la regulación de los fenómenos que acontecen en el marco de la actividad empresarial.

En este orden de ideas, compartimos la opinión de Gómez-Jara Díez, quien sostiene que precisamente por esta incapacidad del Estado para controlar ciertos riesgos creados por la sociedad postindustrial moderna es que resulta necesario alentar la autorregulación empresarial para manejar adecuadamente dichos riesgos ${ }^{17}$. Esto da paso a que desde el propio Estado se fomente la autorregulación.

Como sostiene Coca Vila, la autorregulación no supondría una retirada del Estado, ni la admisión de la incapacidad de regular el mundo empresarial, sino, simplemente, un cambio en el rumbo de la estrategia reguladora. Si el Estado es incapaz de regular desde fuera a las empresas, la única solución posible sería valerse de ellas para conseguir sus objetivos ${ }^{18}$. Es decir, a través de la autorregulación el Estado delegaría en las empresas parte de su función originaria regulatoria, sin que dicha delegación implique una pérdida de la titularidad de dicha función.

Atendiendo a los diversos actores que participan en la formulación de los valores, principios y procedimientos en la organización empresarial, o, visto de otra forma, en la relación dicha

14. PORTER, Michael E. y KRAMEN, Mark R. La creación de valor compartido. Harvard Business Review América Latina: Reimpresión Enero-Febrero, 2011, pp. 5-6.

15. NIETO MARTíN, Adán. El cumplimiento normativo. Manual de Cumplimiento Penal en la Empresa. NIETO MARTÍN, Adán [Dir.]. Valencia: Tirant Lo Blanch, 2015, p. 40.

16. Ibíd., p. 42.

17. GÓMEZ-JARA DIEZ, Carlos. Fundamentos de la responsabilidad penal de las personas jurídicas. BAJO FERNÁNDEZ, Miguel; GÓMEZ-JARA DIEZ, Carlos y FEIJOO SÁNCHEZ, Bernardo José. Tratado de responsabilidad penal de las personas jurídicas. Segunda Edición. Navarra: Editorial Aranzadi, 2016, p. 93.

18. COCA VILA, Ivó. ¿Programas de cumplimiento como forma de autorregulación regulada? SILVA SÁNCHEZ, Jesús María [Director]. Criminalidad de empresa y Compliance. Prevención y reacciones corporativas. Barcelona: Atalier, 2013, p. 46. 
autoorganización guarda con el ordenamiento jurídico y el grado de voluntariedad de la empresa, en la doctrina penal Ulrich Sieber identifica tres modelos de regulación distintos: la autorregulación procedente en exclusiva del mundo de la economía, la coregulación estatal y privada y la regulación puramente estatal. Mientras que la autorregulación en sentido estricto deja a las empresas una amplia discrecionalidad y la regulación estatal fija las condiciones determinantes, la coregulación se caracteriza por el hecho de que las disposiciones estatales crean preceptos más o menos detallados o crean estructuras que estimulan la autorregulación y/o hacen vinculantes medidas de autorregulación. Por esta razón la coregulación se denomina autorregulación regulada, una forma mixta o intermedia entre la autorregulación y la regulación estatal, que se caracteriza por conceder un margen de discrecionalidad a aquellos que deben concretar el programa y por las fórmulas que emplea para estimular o presionar su adopción ${ }^{19}$.

En este orden de ideas, el Compliance en general, y el Compliance penal en particular, es autorregulación, que dependiendo de la exigencia normativa o de la persuasión a su regulación, puede ser calificada como autorregulación voluntaria, estatal o autorregulación regulada. Así, dependiendo de la legislación específica, si el establecimiento de un Compliance penal conlleva a exonerar o atenuar la responsabilidad penal - España, Chile — o administrativa - Italia, Perú- de las personas jurídicas, estaremos frente a un escenario de autorregulación estimulada o coaccionada, o metaregulación, pero en ocasiones de autorregulación regulada ${ }^{20}$.

Ahora bien, en la doctrina penal hay quienes se han opuesto a que el Compliance sea una expresión de autorregulación estimulada, coaccionada

19. SIEBER, Ulrich. Programas de Compliance en el Derecho penal de la empresa. Una nueva concepción para controlar la criminalidad económica. Dogmática penal de Derecho penal económico y Política criminal. Libro homenaje a Klaus Tiedemann. URQUIZO OLAECHEA, José; ABANTO VÁSQUEZ, Manuel y SALAZAR SÁNCHEZ, Nelson [Coord.]. Lima: Fondo Editorial de la Universidad de San Martín de Porres, 2011, pp. 218-219. En la doctrina penal también se proponen otras clasificaciones; al respecto, Vid. NIETO MARTíN, Adán. El cumplimiento normativo. Manual de Cumplimiento Penal en la Empresa. NIETO MARTíN, Adán [Dir.]. Valencia: Tirant Lo Blanch, 2015, p. 36, quien propone la siguiente clasificación: "autorregulación voluntaria", en la que no hay intervención pública alguna destinada, ni tan siquiera, a fomentar o estimular la autorregulación; "autorregulación regulada", en la que el Estado establecería el marco general de la autorregulación, es decir, construye metanormas que regulan como deben establecerse las normas de las empresas y cuáles deben ser sus principios básicos; y "autorregulación estimulada o coaccionada" en la que el Estado a través de sanciones positivas o negativas incentiva la autorregulación. Así mismo, Vid. Coca Vila, Ivó. ¿Programas de cumplimiento como forma de autorregulación regulada? SILVA SÁNCHEZ, Jesús María [Director]. Criminalidad de empresa y Compliance. Prevención y reacciones corporativas. Barcelona: Atalier, 2013, pp. 48-54, quien propone la siguiente clasificación: "autorregulación pura o voluntaria", que hace referencia a aquellos supuestos en los que es la propia empresa la que se dota de un sistema de regulación interno, absolutamente al margen de los poderes públicos, esto es, sin que haya intervención pública alguna dirigida a fomentar, imponer, completar — directa o indirectamente- la autorregulación interna. En todo caso, el Estado permanece al margen, no sólo en la elaboración, sino también en la supervisión, y dado el caso, en la sanción. La "metaregulación", que alude al fenómeno normativo consistente en la determinación o condicionamiento, ya sea ex ante o ex post, de la actividad de autorregulación. Aquí, el Estado condiciona lo normado, ya sea estableciendo internamente una serie de pautas -generalmente a través de principios- a partir de los cuales será la propia empresa la que se autorregula, o bien otorgando incentivos a posteriori en aras de influir en lo internamente normado, $u$ otorgando recompensas para las empresas que se autorregulan, como pueden otorgando ventajas a la hora de valorar y sancionar el incumplimiento normativo en el marco de la empresa. Y, la "Autorregulación regulada o co-regulación —enforced self-regulation-", que alude a la forma de regulación estatal en el mundo empresarial caracterizada por la incorporación del ente privado en el proceso de regulación pero de forma subordinada a los concretos fines o intereses públicos predeterminados por el Estado. Lo relevante es que el Estado continúa siendo el titular de la potestad regulatoria, pero recurre a las empresas para que colaboren con él en la elaboración de cuerpos normativos.

20. En el mismo sentido, Vid. NIETO MARTíN, Adán. El cumplimiento normativo. Manual de Cumplimiento Penal en la Empresa. NIETO MARTíN, Adán [Dir.]. Valencia: Tirant Lo Blanch, 2015, p. 36. 
o metaregulación. Así, García Cavero sostiene que la experiencia mostraría que el recurso directo a las sanciones - administrativas o penales - puede producir, más bien, el efecto indeseado de socavar las motivaciones intrínsecas a cooperar por parte de las empresas indicadas. Por lo tanto, lo más recomendable sería, más bien, mantener la voluntariedad de los procesos de autorregulación de las empresas y la decisión sobre su contenido, reforzando dicha autoconfiguración empresarial interna con un control institucional que acuda fundamentalmente a la supervisión por organismos especializados $y$, solo de manera secundaria, a la imposición de sanciones jurídicas ${ }^{21}$.

Que el Compliance sea autorregulación no implica per se que su naturaleza sea exclusivamente jurídica, sino que el Compliance, como venimos exponiendo, tiene una naturaleza mixta, la que podemos calificar como jurídico-empresarial -el concepto "empresarial" es propio de las Ciencias Empresariales- por cuanto el Compliance también es parte de la gestión empresarial, lo cual se puede observar fácilmente al analizar la relación del Compliance con otros fenómenos corporativos conexos. E incluso, hay algunos autores como Bacigalupo Zapater que sostienen que el Compliance es parte de la cultura empresarial basada en valores, llegando a formular el concepto de valor de cumplimiento del derecho, dándose por supuesto que no hay una cultura de valores que postule eludir el cumplimiento del derecho' ${ }^{22}$.

\section{Aproximación al concepto de Compliance penal.}

El Compliance en general, y el Compliance penal en particular, es un término cuya conceptualización implica una ardua tarea. Así, por ejemplo, Rotsch sostiene que el concepto de Compliance ha protagonizado una carrera vertiginosa ${ }^{23}$, debido a que es uno de los términos más vagos e inexpresivos que se haya acuñado jamás ${ }^{24}$. Incluso, actualmente algunos autores como Coca Vila llegan a sostener que estamos frente a una ciencia, la "ciencia del Compliance"25.

Ahora bien, en la doctrina penal diversos autores proponen definiciones respecto al Compliance. Por ejemplo, Lascuraín Sánchez sostiene que el Compliance es una serie de estrategias normativas, aplicativas e institucionales dirigidos a evitar que en el ejercicio de la actividad social se cometan delitos a favor de la empresa ${ }^{26}$. Por su parte, Khulen señala que, en términos generales, se denomina Compliance a las medidas mediante las cuales las empresas pretenden asegurarse de que sean cumplidas las reglas vigentes para ellas y su personal, que las infracciones se descubran y eventualmente se sancionen. Entendido así en general, no es ni nuevo ni especialmente intrigante que exista Compliance, ni tampoco que se trate con él de Derecho penal, es decir, de evitar la violación de normas reforzadas con pena ${ }^{27}$. Para Gallo el Compliance son sistemas internos de control que tienen algunas empresas

21. GARCÍA CAVERO, Percy. Criminal Compliance. En especial al Compliance anticorrupción y antilavado de activos. Lima: Instituto Pacífico, 2017, pp. 37-38.

22. BACIGALUPO ZAPATER, Enrique. Compliance y Derecho penal. Prevención de la responsabilidad penal de los directivos y de empresas. Buenos Aires: Editorial Hammurabi, 2012, pp. 45-46.

23. ROTSCH, Thomas. "Criminal Compliance”. En: Indret. Revista para el análisis del Derecho № 1/2012. Barcelona: 2012 , p. 2.

24. Vid. NIETO MARTíN, Adán. El cumplimiento normativo. Op. Cit., p. 25.

25. Por todos, Vid. COCA VILA, Ivó. ¿Programas de cumplimiento como forma de autorregulación regulada? Criminalidad de empresa y Compliance. Barcelona: Atelier, 2013, p. 54.

26. LASCURAÍN, Juan Antonio. Compliance, debido control y unos refrescos. Op. Cit., p. 128.

27. KHULEN, LOTHAR. Cuestiones fundamentales de Compliance y Derecho penal. Compliance y Teoría del Derecho penal. KHULEN, Lothar; MONTIEL, Juan Pablo y ORTIZ DE URBINA, Iñigo [Editores]. Madrid: Marcial Pons, 2013, p. 51. 
con el fin de evitar incumplimientos normativos serios por parte de sus empleados y directivos $\mathrm{o}$, de producirse estos, detectarlos ${ }^{28}$. Para Nieto Martín, quien parte de la estandarización de la AS3806-Compliance Programmes, Standards Australia $1988^{29}$, señala que el Compliance es un sistema de gestión empresarial que tiene como objeto prevenir y si resulta necesario, identificar y sancionar las infracciones de leyes, regulaciones, códigos o procedimientos internos que tienen lugar en la organización, promoviendo una cultura de cumplimiento ${ }^{30}$.

Al proponer un concepto de Compliance, es menester tener en consideración que partimos de una noción estrictamente ligada a la gestión empresarial, por ende, el contenido de este concepto apuntará, en primer lugar, a la orientación de la dirección empresarial en determinados objetivos y valores. En este sentido, compartimos la opinión de Sieber quien señala que esto es, resaltando, sobre todo, por el concepto de Business Ethics, el cual describe la realización de valores que van muchas veces por encima de las exigencias normadas legalmente ${ }^{31}$.

Pero en la determinación de los objetivos y valores no se agota el contenido del concepto, el cual también abarca a los procedimientos para la protección organizativa o para el cumplimiento de exigencias legales, aquí es donde cobran relevancia conceptos como Codes of Conduct que constituyen pautas generales de conducta. En resumen, a partir de estas nociones, el concepto de difícil traducción, Compliance - de manera literal "programa de cumplimiento" o "programa de respeto de reglas" - refiere a las medidas normativas ${ }^{32}$ — de la propia persona jurídica- que establecen procedimientos internos de la empresa cuyo objeto es el respeto de los objetivos sobre todo legales - cumplimiento de la legalidad - , pero también éticos — cumplimiento con las normas internas y políticas de la empresa-, trazados por la dirección empresarial — cultura de cumplimiento- ${ }^{33}$.

Desde nuestro punto de vista, el Compliance define a aquel sistema normativo interno de gestión empresarial, tendente a evitar que la empresa y sus miembros incurran en riesgos legales - por ejemplo: civiles, administrativos, societarios, laborales, entre otros-y de vulneración de la normativa interna de la empresa, pero también que orienta la actuación de la empresa y sus funcionarios hacia una determinada cultura de integridad, de la cual la cultura de

28. GALLO, Alonso. Los programas de cumplimiento. Estudios sobre las reformas del Código Penal. DÍAZ-MAROTO [Dir.] Madrid: Civitas, 2011, p. 148.

29. Debemos señalar que actualmente dicha norma técnica de estandarización se encuentra desfasada, siendo la norma técnica vigente la Australian Standard 3806:2006, Compliance Programs.

30. NIETO MARTíN, Adán. El cumplimiento normativo. Manual de Cumplimiento Penal en la Empresa. Op. Cit., p. 26.

31. En similar sentido, aunque con ciertos matices, Vid. SIEBER, Ulrich. Programas de Compliance en el Derecho penal de la empresa. Una nueva concepción para controlar la criminalidad económica. Dogmática penal de Derecho penal económico y Política criminal. Libro homenaje a Klaus Tiedemann. URQUIZO OLAECHEA, José; ABANTO VÁSQUEZ, Manuel y SALAZAR SÁNCHEZ, Nelson [Coord.]. Lima: Fondo Editorial de la Universidad de San Martín de Porres, 2011, p. 208.

32. En este sentido, Vid. LASCURAÍN, Juan Antonio. Compliance, debido control y unos refrescos. El Derecho penal económico en la era del Compliance. ARROYO ZAPATERO, Luis y NIETO MARTÍN, Adán [Directores]. Valencia: Tirant Lo Blanch, 2013, p. 129.

33. En similar sentido, aunque con ciertos matices, Vid. SIEBER, Ulrich. Programas de Compliance en el Derecho penal de la empresa. Una nueva concepción para controlar la criminalidad económica. Dogmática penal de Derecho penal económico y Política criminal. Libro homenaje a Klaus Tiedemann. URQUIZO OLAECHEA, José; ABANTO VÁSQUEZ, Manuel y SALAZAR SÁNCHEZ, Nelson [Coord.]. Lima:Fondo Editorial de la Universidad de San Martín de Porres, 2011, p. 208. 
cumplimiento forma parte; $y$, cuando lo que se quiere evitar o prevenir son los riesgos penales, estaremos frente a un Compliance penal. Así, el sistema de Compliance es un concepto amplio que abarca al Compliance penal, o, si se quiere ver de otro modo, al programa de cumplimiento normativo en materia penal. La tendencia se orienta en este campo a que las empresas -el sector privado- asuman una función preventiva pública, basada en códigos de conducta, programas de cumplimiento - penales, administrativos, laborales, de gestión de riesgos en general-y en la vigilancia de la legalidad.

\section{II. ¿PARA QUÉ SIRVE EL COMPLIANCE PENAL?}

\section{Funciones del Compliance penal.}

En una reciente publicación, García Cavero analiza las funciones del Compliance desde el punto de vista de cómo repercuten en el sistema jurídico penal, sosteniendo una doble clasificación. En primer lugar, la función de prevención de delitos, por cuanto las medidas preventivas adoptadas deben llevar efectivamente a una reducción del número de infracciones penales en el ámbito de la empresa, lo que corresponde con lo que, en el plano criminológico, se denomina como prevención situacional. En segundo lugar, la función de confirmación de la normativa penal, por cuanto si un delito es cometido en el marco de la actividad empresarial a pesar de la labor de prevención, a la empresa le corresponderá mostrar una actitud de fidelidad al derecho mediante la adopción de medidas de mitigación y compensación de los daños producidos como consecuencia del ilícito penal ${ }^{34}$. Sin perjuicio de lo anterior, consideramos que el Compliance penal cumple una tercera función, derivada del Compliance en general, la cual es coadyuvar en el fomento de una cultura de cumplimiento de la legalidad, pero en el ámbito penal.

\subsection{Función de prevención de delitos.}

La principal función del Compliance penal es prevenir y descubrir las actividades ilícitas que puedan realizar los directivos y empleados de una empresa ${ }^{35}$. Esta función de prevención de delitos por parte de los directivos de la empresa, así como de los empleados y subordinados, no debe confundirse como un mecanismo de protección o deslinde de responsabilidad del superior jerárquico, de modo que la imputación recaiga únicamente sobre los subordinados.

Como bien explica Thomas Rotsch, quien tome solo en consideración el objetivo de la evitación de responsabilidad como tal corre el peligro de pasar por alto que con una semejante estrategia de Compliance dirigida de forma singular puede decaer ciertamente la responsabilidad penal de la dirección empresarial. Pero dado que la dirección de la empresa generalmente puede descargarse a través de una organización cuidadosa y en especial a través de la delegación, la responsabilidad penal no se diluye sin dejar rastro en la empresa, sino que en cierto modo se transfiere a los trabajadores subordinados. La supuesta evitación de responsabilidad sería entonces un mero traslado de responsabilidad que afectaría penalmente a otros sujetos, lo cual desde el punto de vista empresarial puede ser igualmente desastroso ${ }^{36}$. Por lo tanto, no le falta razón a García Cavero cuando señala que seguir una perspectiva que ponga la mirada en la gestión de responsabilidad en lugar de la gestión del riesgo, lo que finalmente provocaría es un simple traslado de

34. GARCÍA CAVERO, Percy. Criminal Compliance. En especial Compliance anticorrupción y Compliance antilavado de activos. Lima: Instituto Pacífico, 2017, p. 84.

35. En este sentido, Vid. NIETO MARTíN, Adán. Cumplimiento normativo, criminología y responsabilidad penal de las personas jurídicas. Nieto Martín, Adán [Dir.] Manual de Cumplimiento Penal en la Empresa. VALENCIA: Tirant Lo Blanch, 2015, p. 50.

36. ROTSCH, Thomas. Criminal Compliance. En: Indret. Revista para el análisis del Derecho N 1/2012. Barcelona: 2012, pp. 5-6. 
la imputación penal de los directivos a otros trabajadores de la empresa ${ }^{37}$.

\subsection{Función de confirmación de la normativa penal.}

El Compliance penal también tiene como función el coadyuvar a la confirmación de la normativa penal, pero en el seno de la empresa. García Cavero señala que esto se lleva a cabo por cuanto el Compliance penal no se reduce, como en general con cualquier corporate Compliance, a implementar medidas de prevención de delitos, sino que también debe ocuparse de detectar las infracciones penales que pudiesen haberse cometido por los trabajadores de la empresa y gestionar sus consecuencias de forma tal que se evidencie también en estos casos la voluntad de la empresa de actuar conforme a la legalidad ${ }^{38}$.

Para llevar a cabo la función de confirmación de la normativa penal, el Compliance penal debe implementar medidas adicionales y dirigidas a detectar las infracciones penales, las cuales, desde un punto de vista abstracto, no se hubieran podido evitar con las concretas medidas de prevención adoptadas. Para este fin, es fundamental que el Compliance penal cuente con un canal de denuncias -Whistleblowing - , un código de investigaciones internas y concretos protocolos de actuación ante la verificación de la comisión de un delito ${ }^{39}$.

\subsection{Función de coadyuvar en la formación de una cultura de cumplimiento, pero en el ámbito penal.}

El Compliance, en general, tiene como uno de sus propósitos, tal vez el más importante, el fomento de una cultura de cumplimiento en el seno de la empresa. Esto se hace visible en mayor medida, cuando existe un verdadero compromiso de la Alta Dirección - top at the top-en orientar la actividad de la empresa generando un valor compartido y respetando, y haciendo respetar en el seno de la empresa, los propios valores y principios que ella misma se ha trazado en su Código ético, fomentándose de este modo una cultura de cumplimiento.

Ahora bien, por lo que al Compliance penal respecta, siendo que su objeto de acción es delimitado a la gestión de riesgos penales, pues no puede desconocerse que comparte con el Sistema de Compliance el propósito de fomentar la cultura de cumplimiento. Por ende, el Compliance penal tiene entre sus funciones el coadyuvar al fomento de la cultura de cumplimiento en el seno de la empresa, pero delimitado al cumplimiento normativo en materia penal.

En este sentido, compartimos la opinión de Gómez-Jara Diez cuando señala que debe tenerse en cuenta que, en ocasiones, las personas jurídicas carecen de una adecuada cultura de Compliance - que equivale a una cultura de incumplimiento de la legalidad-. Cuando esto ocurre, la probabilidad de que se comentan delitos en el seno de las mismas aumenta exponencialmente. Pues precisamente porque una cultura empresarial puede cuestionar la validez o legitimidad del derecho, resulta razonable e incluso necesario culparlas cuando como resultado de dicha cultura empresarial se produce un daño jurídicamente relevante ${ }^{40}$.

\section{El Compliance penal en la imputación de responsabilidad penal/administrativa de las personas jurídicas.}

37. GARCÍA CAVERO, Percy. Criminal Compliance. En especial Compliance anticorrupción y Compliance antilavado de activos. Lima: Instituto Pacífico, 2017, p. 84.

38. Ibíd., p. 96.

39. Ibid., p. 97.

40. GÓMEZ-JARA DIEZ, Carlos. Fundamentos de la responsabilidad penal de las personas jurídicas. BAJO FERNÁNDEZ, Miguel; GÓMEZ-JARA DIEZ, Carlos y FEIJOO SÁNCHEZ, Bernardo José. Tratado de responsabilidad penal de las personas jurídicas. Segunda Edición, Navarra: Editorial Aranzadi, 2016, p. 95. 


\subsection{Sistemas de imputación de responsabilidad penal de las personas jurídicas: Derecho comparado, doctrina y jurisprudencia.}

En el Derecho comparado podemos apreciar que cada vez es mayor el número de legislaciones que responsabilizan a las personas jurídicas por los delitos cometidos por sus directivos, representantes y subordinados, en beneficio de estas.

Esta responsabilidad jurídica puede ser "administrativa" o "penal", según la opción político criminal que adopte cada Estado para hacer frente a la criminalidad de empresa ${ }^{41}$.

Elementos en común de ambas responsabilidades "penal o administrativa" de las personas jurídicas, es que derivan de la comisión de un delito previsto en el Código penal o en la legislación penal complementaria, cometido en beneficio de las personas jurídicas, en donde la sanción la impone un juez penal en el marco de un proceso penal.

En la doctrina penal se han elaborado diversas "tesis" para la atribución de responsabilidad penal a las personas jurídicas, planteando la atri- bución de responsabilidad penal a la persona jurídica a través de un injusto propio de la organización empresarial o, en otros casos, atribuyendo responsabilidad penal a la persona jurídica a partir de un injusto penal cometido por una persona natural.

Señala Hernández Basualto que existen dos modelos legislativos ideales de responsabilidad penal de personas jurídicas: por un lado un modelo de responsabilidad derivada — sistema vicarial-, conforme al cual se hace recaer sobre la persona jurídica la responsabilidad penal de una persona natural en virtud de algún criterio de conexión entre una y otra, generalmente la circunstancia de ser la persona natural órgano o al menos subordinado del ente moral; $y$, por otra parte, un modelo de responsabilidad autónoma u originaria — sistema de culpabilidad de empresa-, según el cual la responsabilidad surge directamente de una conexión entre el hecho prohibido y una característica de - o un cierto estado de cosas en - la entidad, siendo irrelevante la eventual responsabilidad de una persona natural ${ }^{42}$.

El primer modelo de imputación, vicarial o de transferencia de responsabilidad ${ }^{43}$, la culpabi-

41. En este orden de ideas, conviene precisar que en la doctrina penal se sostiene que el fundamento que en política criminal se ha esbozado para sancionar penalmente a las personas jurídicas radica en la necesidad del legislador penal de castigar los delitos socioeconómicos, financieros, ambientales, fiscales, entre otros delitos pensados a ser cometidos en seno de una persona jurídica; en la urgencia de buscar nuevas vías de lucha contra la criminalidad organizada; por cuestiones de legalidad, sobre todo a causa de los problemas planteados en los delitos especiales cometidos en el seno de una persona jurídica. Sobre ello, Vid. GONZÁLEZ CUSSAC, José Luis. El modelo español de Responsabilidad Penal de las Personas Jurídicas. Anuario de Derecho Penal Económico y de la Empresa. Número 3. Lima: Centro de Estudios de Derecho Penal Económico y de la Empresa-CEDPE, 2015, p. 98. En el mismo orden de ideas, Vid. HEINE, Günter. La responsabilidad penal de las Empresas: Evolución internacional y Consecuencias nacionales. Anuario de Derecho Penal '96. Responsabilidad penal de las Personas Jurídicas. Lima: Editorial Grijley, 1996, p. 22; quien sostiene que el fundamento político criminal para sancionar penalmente a las personas jurídicas se encuentra en las dificultades de investigación del delito, debido a que en las personas jurídicas, sobre todo en aquellas de significativas dimensiones estructurales, es usual que con motivo de la descentralización y diferenciación funcional de competencias, se dispersen las actividades operativas, la presión de información y el poder de decisión, con lo cual, y de conforme a nuestro Derecho penal tradicional, resultará jurídicamente imposible sostener una imputación concreta contra una persona individual.

42. HERNÁNDEZ BASUALTO, Héctor. La introducción de la responsabilidad penal de las personas jurídicas en Chile. En: Política criminal Vol. V, № 9. Santiago de Chile: Julio 2010, pp. 216-217.

43. A favor del sistema vicarial, Vid. ZUGALDÍA ESPINAR, José Miguel. La admisión de la Responsabilidad Penal de las Personas Jurídicas: Un pilar básico del moderno Derecho penal económico. Nuevas Tendencias del Derecho Penal Económico y de la Empresa. Lima: ARA Editores, 2005, p. 456. 
lidad de la persona natural se transferirá a la persona jurídica. Este modelo también es conocido como responsabilidad por atribución ${ }^{44}$.

Los presupuestos básicos o generales de este modelo, que podrían variar según el tipo de legislación, son los siguientes: (a) la comisión de una infracción por parte de un empleado de la corporación, (b) que esta infracción se haya cometido en el ejercicio de las funciones que le han sido atribuidas, (c) con la intención de obtener algún tipo de ventaja, beneficio para la empresa o infringiendo una obligación que correspondía a la empresa ${ }^{45}$.

Las plasmaciones legislativas del sistema vicarial difieren principalmente en la determinación del círculo de personas cuyo comportamiento da lugar a la responsabilidad de la empresa. En algunos sistemas como el de Francia o el Reino Unido - salvo en el homicidio de la corporación y en la Bribery Act- la responsabilidad se produce únicamente cuando el comportamiento del infractor ha sido realizado por un directivo o persona perteneciente al "cerebro" de la corporación -brain area-; esto es, el modelo anglosajón del alter-ego doctrine, en donde se considera que determinadas personas físicas son el alter-ego de la persona jurídica, de tal manera que, en cierta medida, sus comportamientos son los de aquella. Dichas personas serían las que de conformidad con un criterio normativo civil, representan de hecho o de derecho a la persona jurídica ${ }^{46}$.

Mientras que en otras legislaciones, como en Estados Unidos de América, cualquier empleado o incluso cualquier persona que obre por cuenta de la empresa - por ejemplo un agente comercial contratado- puede dar lugar a responsabilidad - respondeat superior- ${ }^{47}$. $\mathrm{Al}$ respecto, William Laufer señala que los Tribunales consideran que las empresas son penalmente responsables de las conductas de sus empleados, siempre que éstos actúen en el marco de sus competencias y con la intención de beneficiar a la empresa. La teoría del superior que responde - respondeat superior, que proviene del Derecho de daños- considera que las empresas son los representados y los directivos, supervisores y empleados, los representantes. Conforme al Derecho Federal, las intenciones de los representantes simplemente se imputan o atribuyen al representado. La legislación estatal varía, pero en la mayoría de éstas se requiere que las actuaciones estuvieran autorizadas, solicitadas, ejecutadas o toleradas por el consejo de administración o por altos directivos ${ }^{48}$.

44. Al respecto, Vid. SILVA SÁNCHEZ, Jesús María. La responsabilidad penal de las Personas Jurídicas en el Derecho español. Fundamentos de Derecho Penal de la Empresa. Buenos Aires: Editorial B de F, 2013, pp. 254 y ss.

45. NIETO Martín, Adán. "Cumplimiento normativo, criminología y responsabilidad penal de las Personas Jurídicas". NIETO Martín, Adán (Director). Manual de Cumplimiento Penal en la Empresa. Valencia: Tirant lo Blanch, 2015, p. 69.

46. Cfr. GÓMEZ-JARA DIEZ, Carlos. La nueva responsabilidad penal de las Personas Jurídicas en el Derecho penal español (artículo 31BIS del Código penal). GOMEZ-JARA DIEZ, Carlos (Editor), Modelos de Responsabilidad Penal de las Personas Jurídicas. Propuestas globales contemporáneas. Lima: ARA Editores, 2012, pp. 310-311.

47. Op. Cit., pp. 69 y ss.

48. LAUFER, William S. La culpabilidad empresarial y los límites del Derecho. Para este autor, las HEINE, Günter; LAMPE, Ernst Joachim; LAUFER, William S.; GÓMEZ-JARA DIEZ, Carlos y STRUDLER, Alan. Modelos de responsabilidad penal de las personas jurídicas. Propuestas globales contemporáneas. Lima: Ara Editores, 2012, p. 140, sostiene que las razones por las cuales el Derecho penal de los Estados Unidos de América prefiere la responsabilidad vicarial, son dos. En primer lugar, razones de conveniencia judicial y utilidad; en segundo lugar, las presunciones de que se logra un compromiso justo a la hora de ubicar el riesgo y las pérdidas económicas, así como la presunción de que la teoría del respondeat superior induce a las organizaciones para que hagan efectiva la responsabilidad individual, pp. 141-142. 
El modelo de responsabilidad penal vicarial es objeto de una severa crítica por parte de la doctrina penal, especialmente porque se considera contraria al principio de culpabilidad penal. Así, Feijoo Sánchez señala que los inconvenientes del modelo vicarial, tanto desde el punto de vista de la legitimación jurídica, como de sus consecuencias prácticas, obedecen a una misma debilidad conceptual de partida. Se mantiene en clave estrictamente individualista -identificación entre individuo y organización- por lo que no se diferencia adecuadamente entre individuo -infracción o responsabilidad individual- y organización - defecto organizativo o responsabilidad supraindividual-. Las consecuencias son, en primer lugar, que el modelo no deja al margen a que pueda declararse responsabilidad corporativa sin encontrar un culpable individual. Pero también conduce, en segundo lugar, a una excesiva responsabilidad penal cuando tiene como consecuencia que todo delito individual sin excepción sea definido como un delito corporativo. El modelo vicarial peca tanto por defecto como por exceso ${ }^{49}$.

En la doctrina anglosajona también se cuestiona el sistema de imputación vicarial, postulándose modelos de culpabilidad de empresa. Así, William Laufer señala que la doctrina está tomando en cuenta modelos de culpabilidad proactivos, reactivos, basados en la cultura o en la política corporativa ${ }^{50}$. Incluso en la jurispru- dencia norteamericana en alguna ocasión también se cuestionó el modelo de imputación vicarial de responsabilidad penal de las personas jurídicas. Así, en el caso United States vs. Bank of New England -1987- la Corte de Apelación estableció que se presume que el Banco posee un tipo de conocimiento que consiste en el conocimiento colectivo de todos sus empleados. El conocimiento agregado de los empleados constituye el conocimiento empresarial. Ningún Tribunal se ha alejado tanto de la regla del respondeat superior ${ }^{51}$.

El segundo modelo es el sistema de culpabilidad de empresa, en el cual se fundamenta la responsabilidad penal del ente colectivo a través de factores que tienen que ver con la propia corporación. Es decir, fundamenta un injusto de la propia persona jurídica. Para los partidarios de este modelo, las personas jurídicas tienen capacidad de acción y culpabilidad. A este modelo también se le conoce como responsabilidad por el hecho propio ${ }^{52}$.

Gómez-Jara Diez señala que este modelo parte de la necesidad de construir un concepto de culpabilidad jurídico penal empresarial, debido a que se considera que en un genuino Derecho penal empresarial la culpabilidad se constituye en fundamento y límite de la imposición de un determinado tipo de sanciones penales - las penas - a la empresa y éstas

49. FEIJOO SÁNCHEZ, Bernardo. El delito corporativo en el Código penal español. Cumplimiento normativo y fundamento de la responsabilidad penal de las empresas. Navarra: Editorial Aranzadi, 2015, p. 50.

50. LAUFER, William S. La culpabilidad empresarial y los límites del Derecho. Para este autor, las HEINE, Günter; LAMPE, Ernst Joachim; LAUFER, William S.; GÓMEZ-JARA DIEZ, Carlos y STRUDLER, Alan. Modelos de responsabilidad penal de las personas jurídicas. Propuestas globales contemporáneas. Lima: Ara Editores, 2012, p. 141. Este autor señala que la culpabilidad empresarial proactiva -CEP- postula que la culpabilidad se determina en función de la razonabilidad de las medidas adoptadas para prevenir el delito; la culpabilidad empresarial reactiva -CER- postula que la culpabilidad se determina en función de la razonabilidad de los pasos tomados como reacción a descubrimiento del delito; la culpabilidad por la ética empresarial -CEE-, postula que la culpabilidad se deriva del ethos corporativo, la cultura empresarial o la identidad corporativa; y, la culpabilidad por la política empresarial -CPE-, postula que la intencionalidad corporativa se basa en las decisiones y las oportunidades que son comunicadas a través de la política empresarial. pp. 144-148

51. Ibíd., p. 141.

52. Al respecto, Vid. SILVA SÁNCHEZ, Jesús María. La responsabilidad penal de las Personas Jurídicas en el Derecho español. Fundamentos de Derecho Penal de la Empresa. Buenos Aires: Editorial B de F, 2013, pp. 254 y ss. 
son las únicas que contribuyen al completo restablecimiento comunicativo de la vigencia del ordenamiento jurídico ${ }^{53}$; en consecuencia, en otros ordenamientos jurídicos como el administrativo, civil, etc., no habría necesidad de desarrollar ni fundamentar un concepto de culpabilidad de empresa.

Para el sistema de imputación basado en la culpabilidad empresarial, el delito de la persona física es el presupuesto, no el fundamento de la responsabilidad penal de las personas jurídi$\mathrm{Cas}^{54}$. En el mismo sentido se ha pronunciado la jurisprudencia del Tribunal Supremo Español en el Pleno Jurisdiccional del 29.02.2016, donde sostuvo que:

"En ambos motivos el Recurso incurre en una clara confusión acerca de la tipicidad de la intervención de la persona jurídica recurrente, que no estriba exclusivamente en la comisión del delito contra la salud pública atribuida a sus administradores, de hecho y de derecho, infracción que opera como requisito precedente necesario para el ulterior pronuncia- miento acerca de la responsabilidad peal propia de la entidad medida en términos de incumplimiento de su obligación de poner los medios para la evitación de delitos en su seno (...) Una vez más procede la desestimación ya que también en este caso el Recurso incurre en el error, expuesto en su momento, de los restantes formalizados por las personas jurídicas condenadas, al confundir las conductas típicas de las personas físicas con el fundamento de la responsabilidad penal de la persona jurídica" ${ }^{\prime \prime 5}$.

En relación al análisis dogmático del Derecho comparado, haremos alusión únicamente a cuatro legislaciones que reconocen la responsabilidad "penal"56 y "administrativa" ${ }^{157}$ de las personas jurídicas por los delitos cometidos por sus directivos, representantes y subordinados.

En Italia el legislador introdujo la responsabilidad "administrativa" de las personas jurídicas con el Decreto Legislativo 231 del año $2001^{58}$. Los criterios de imputación de la responsabilidad "administrativa" a las personas jurídicas se

53. GÓMEZ JARA-DIEZ, Carlos. La Culpabilidad penal de la Empresa. Madrid: Marcial Pons Ediciones Jurídicas y Sociales, 2005, p. 69.

54. GÓMEZ-JARA DÍEZ, Carlos. El Tribunal Supremo ante la Responsabilidad Penal de las Personas Jurídicas. El inicio de una larga andadura. Navarra: Aranzadi, 2017, p. 56.

55. Comentarios a dicha jurisprudencia, en: GÓMEZ-JARA DíEZ, Carlos. El Tribunal Supremo ante la Responsabilidad Penal de las Personas Jurídicas. El inicio de una larga andadura. Navarra: Aranzadi, 2017, pp. 49-96.

56. En la doctrina se han formulado diversas críticas en torno a la atribución de responsabilidad "penal" a las personas jurídicas. Por todos, Vid. GRACIA MARTIN, Luis. Críticas de las modernas construcciones de una mal llamada responsabilidad penal de las personas jurídicas. En: Revista Electrónica de Ciencia Penal y Criminología ISSN 16950194, Nº 18, 2016, pp. 1-95.

57. No entraremos a la discusión existente en dichos países respecto a si la responsabilidad que se imputa a las personas jurídicas es "administrativa" o si estamos frente a un fraude de etiquetas en donde lo que se imputa es una auténtica responsabilidad "penal".

58. Por todos, Vid. De Vero, Giancarlo. La responsabilitá penale delle persone giuridiche. Grosso/Padovani/Pagliaro [Dir.]. Trattato di diritto penale. Parte generale. Milano: Giuffré Editore, 2008, pp. 3-30 y 305-336. Así, también, Vid. FOFFANI, Luigi. La nueva responsabilidad (¿penal?) de las personas jurídicas en Italia. Dogmática penal de Derecho penal económico y Política criminal. Libro homenaje a Klaus Tiedemann. URQUIZO OLAECHEA, José; ABANTO VÁSQUEZ, Manuel y SALAZAR SÁNCHEZ, Nelson [Coord.]. Lima: Fondo Editorial de la Universidad de San Martín de Porres, 2011, pp. 115-124. 
encuentran regulados en el artículo $5^{59}$. En el caso de Perú, con la Ley 30424 del 17.03.2016, modificada por el Decreto Legislativo 1352, del 07.01.2017, se introdujo, al igual que en Italia, la responsabilidad "administrativa" de las personas jurídicas, para los delitos de cohecho, cohecho activo transnacional, lavado de activos y financiamiento del terrorismo. Los criterios de imputación de responsabilidad penal se encuentran regulados en el artículo $3^{60}$, bajo criterios similares a los establecidos en la legislación italiana.

En el caso de España, desde la Ley Orgánica $5 / 2010$ se reconoce la responsabilidad "penal" de las personas jurídicas. Ahora bien, dicho sistema de responsabilidad penal fue modificado por el Ley Orgánica 1/201561. Los criterios de imputación se encuentran regulados en el artículo 31 bis numeral 1) del Código penal español, en términos similares a la legislación italiana y peruana.

En el caso de Chile desde el año 2009, con la Ley 20393, se introdujo la responsabilidad penal de las personas jurídicas. Los criterios de imputación se encuentran regulados en el artículo $3^{62}$ de la referida Ley, siendo que estos criterios hacen alusión a la responsabilidad penal directa de la persona jurídica, es decir, se trata sistema

59. El texto del artículo $5^{\circ}$ del Decreto Legislativo 231 es el siguiente: "1. L'ente è responsabile per i reati commessi nel suo interesse o a suo vantaggio: a) da persone che rivestono funzioni di rappresentanza, di amministrazione o di direzione dell'ente o di una sua unità organizzativa dotata di autonomia finanziaria e funzionale nonché da persone che esercitano, anche di fatto, la gestione e il controllo dello stesso; b) da persone sottoposte alla direzione o alla vigilanza di uno dei soggetti di cui alla lettera a). 2. L'ente non risponde se le persone indicate nel comma 1 hanno agito nell'interesse esclusivo proprio o di terzi".

60. El texto del artículo 3 de la Ley 30424 es el siguiente: "Las personas jurídicas son responsables administrativamente por los delitos señalados en el artículo 1, cuando estos hayan sido cometidos en su nombre o por cuenta de ellas y en su beneficio, directo o indirecto, por: a. Sus socios, directores, administradores de hecho o derecho, representantes legales o apoderados de la persona jurídica, o de sus filiales o subsidiarias. b. La persona natural que, estando sometida a la autoridad y control de las personas mencionadas en el literal anterior, haya cometido el delito bajo sus órdenes o autorización. c. La persona natural señalada en el literal precedente, cuando la comisión del delito haya sido posible porque las personas mencionadas en el literal a. han incumplido sus deberes de supervisión, vigilancia y control sobre la actividad encomendada, en atención a la situación concreta del caso. Las personas jurídicas que tengan la calidad de matrices serán responsables y sancionadas siempre que las personas naturales de sus filiales o subsidiarias, que incurran en cualquiera de las conductas señaladas en el primer párrafo, hayan actuado bajo sus órdenes, autorización o con su consentimiento. Las personas jurídicas no son responsables en los casos en que las personas naturales indicadas en el primer párrafo, hubiesen cometido los delitos previstos en el artículo 1, exclusivamente en beneficio propio o a favor de un tercero distinto a la persona jurídica".

61. Sobre la responsabilidad penal de las personas jurídicas en el Derecho español, por todos Vid. AGUDO FERNÁNDEZ, Enrique; JAÉN VALLEJO, Manuel y PERRINO LÓPEZ, Ángel Luis. Derecho penal de las personas jurídicas. Madrid: Editorial Dykinson SL., 2016, pp. 19-62.

62. El texto del artículo 3 de la Ley 20393 es el siguiente: “Las personas jurídicas serán responsables de los delitos señalados en el artículo 1 que fueren cometidos directa e inmediatamente en su interés o para su provecho, por sus dueños, controladores, responsables, ejecutivos principales, representantes o quienes realicen actividades de administración y supervisión, siempre que la comisión del delito fuere consecuencia del incumplimiento, por parte de ésta, de los deberes de dirección y supervisión. Bajo los mismos presupuestos del inciso anterior, serán también responsables las personas jurídicas por los delitos cometidos por personas naturales que estén bajo la dirección o supervisión directa de alguno de los sujetos mencionados en el inciso anterior. Se considerará que los deberes de dirección y supervisión se han cumplido cuando, con anterioridad a la comisión del delito, la persona jurídica hubiere adoptado e implementado modelos de organización, administración y supervisión para prevenir delitos como el cometido, conforme a lo dispuesto en el artículo siguiente. Las personas jurídicas no serán responsables en los casos que las personas naturales indicadas en los incisos anteriores, hubieren cometido el delito exclusivamente en ventaja propia o a favor de un tercero". 
de responsabilidad fundamentado en la noción de culpabilidad de la empresa ${ }^{63}$.

Salvo el caso de la legislación Chilena, si realizamos una lectura aislada de las legislaciones italiana, peruana y española, nos llevaría prima facie a sostener, equivocadamente, que en dichas legislaciones se sigue un sistema vicarial de atribución de la responsabilidad administrativa a las personas jurídicas ${ }^{64}$. Sin embargo, una lectura sistemática de dichas legislaciones nos lleva a la conclusión correcta. Por ejemplo, una lectura en clave garantista y de reafirmación del principio de culpabilidad penal de los artículos 3 y 6 -donde se regula la posición de los "apicales" y el modelo de Compliance- del Decreto Legislativo italiano 231; de los artículos 3 y 17 numerales 1) y 4) de la Ley peruana 30424 y del artículo 31 bis numeral 2) del Código Penal español, nos permite sostener válidamente que en dichos sistemas legales se reconoce la responsabilidad penal/administrativa de las personas jurídicas fundamentada en el principio de culpabilidad de la empresa, donde el ilícito de la persona natural no constituye el fundamento de la imputación, sino únicamente el presupuesto de la misma, siendo que a la persona jurídica se le imputa su propio delito, lo que en doctrina se ha denominado "delito corporativo".

En la doctrina penal, Feijoo Sánchez propone el concepto de delito corporativo. Así, señala que la pena no se impone a un colectivo - no es una pena colectiva-, sino a una entidad con cierta identidad propia y la multa afecta al patrimonio de esta, sin que nunca se pueda trasladar al colectivo. Cuando hablamos de un delito corporativo ha de haber algo más que una acción conjunta o colectiva ${ }^{65}$. Existen razones organizativo-estructurales que, junto a la infracción individual, explican el hecho delictivo. Esto es lo que en esencia ha de entenderse por delito corporativo, como hecho que genera una responsabilidad penal adicional en la medida en la que no solo tiene una explicación adicional vinculada al trabajador o administrador concreto que ha delinquido. A la pregunta de qué tipo de defecto estructural es el que genera responsabilidad, hay que responder que se trata de condiciones estructurales que permiten asegurar el cumplimiento de la legalidad por parte de la organización. Lo relevante a efectos jurídico-penales es que se llegue a una situación incompatible con el desarrollo de una política o cultura corporativa de cumplimiento de la legalidad penal y que tal situación se concrete o realice en la comisión de un hecho delictivo por parte de un integrante de la empresa ${ }^{66}$.

El concepto de delito corporativo fue asumido por la jurisprudencia del Tribunal Supremo Español en la Sentencia del 16.03.2016, en donde sostuvo que:

63. Para mayores referencias sobre la responsabilidad penal de las personas jurídicas en Chile, por todo Vid. HERNÁNDEZ BASUALTO, Héctor. La introducción de la responsabilidad penal de las personas jurídicas en Chile. En: Política Criminal Vol. V, № 9. Santiago de Chile: Julio 2010, pp. 216-217.

64. De hecho, de una lectura de la Exposición de Motivos de la norma peruana, se puede apreciar que el legislador se aparta del sistema vicarial de transferencia de responsabilidad a la persona jurídica; e incluso sostiene, textualmente, que: "Para que opere la responsabilidad de la persona jurídica, se exige la concurrencia de 2 elementos: (i) Hecho de conexión: el delito debe ser cometido por quienes ostentan poder de dirección o representación o sus subordinados en el ejercicio de sus funciones y que le haya reportado un beneficio directo o indirecto, que puede ser de carácter económico o no, como puede ser posicionamiento estratégico en el mercado; y, (ii) Culpabilidad por defecto de organización: se exige la implementación efectiva de un programa de prevención o cumplimiento, en caso esto no ocurra este elemento de habría configurado". La Exposición de Motivos se encuentra disponible en: $<$ http://www.congreso.gob.pe/Docs/comisiones2016/ConstitucionReglamento/files/dl 1352 (1).pdf $>$

65. FEIJOO SÁNCHEZ, Bernardo. El delito corporativo en el Código penal español. Cumplimiento normativo y fundamento de la responsabilidad penal de las personas jurídicas. Segunda Edición. Navarra: Editorial Civitas, pp. 66-67.

66. Ibíd., pp. $70-71$. 
"La responsabilidad de la persona jurídica ha de hacerse descansar en un delito corporativo construido a partir de la comisión de un previo delito por la persona física, pero que exige algo más, la proclamación de un hecho propio con arreglo a criterios de imputación diferenciados y adaptados a la especificidad de la persona colectiva. De lo que se trata, en fin, es de aceptar que solo a partir de una indagación por el Juez instructor de la efectiva operatividad de los elementos estructurales y organizativos asociados a los modelos de prevención, podrá construirse un sistema respetuoso con el principio de culpabilidad ${ }^{\prime \prime 67}$.

\section{atribución de responsabilidad penal/ administrativa de las personas jurídicas.}

El Compliance penal cumple una función en la imputación de responsabilidad penal o administrativa de las personas jurídicas, es decir, que tiene sentido para efectos de la atribución de responsabilidad jurídica. Esta afirmación conlleva, implícitamente, la aceptación de una relación entre Compliance penal y responsabilidad de las personas jurídicas ${ }^{68}$. Esto conlleva a la pegunta de cuál es la función del Compliance penal en materia de responsabilidad penal/administrativa de las personas jurídicas.

Al respecto, Nieto Martín sostiene que esto de-

\subsection{Ubicación del Compliance penal en la}

67. Comentarios a dicha jurisprudencia, en: Gómez-Jara Díez, Carlos. El Tribunal Supremo ante la Responsabilidad Penal de las Personas Jurídicas. El inicio de una larga andadura. Navarra: Aranzadi, 2017, pp. 97-133.

68. Cfr. ORTIZ DE URBINA GIMENO, Iñigo. Sanciones penales contra empresas en España (Hispánica societas delinquere potest). KHULEN, Lothar; MONTIEL, Juan Pablo y ORTIZ DE URBINA GIMENO, Iñigo [Editores]. Compliance y teoría del Derecho Penal. Madrid: Marcial Pons, 2013, p. 264. Para este autor, "frente a lo que parece ser la posición mayoritaria, la relación entre Compliance y responsabilidad penal de las personas jurídicas (en adelante RPPJ) es contingente y, en cualquier caso, no decisiva. Es decir: puede haber Compliance con o sin RPPJ y no es claro que la RPPJ suponga una ventaja sobre el régimen administrativo sancionador dirigido a las empresas menos aún que sea un grado de ventaja sobre otras posibilidades de intervención que permitan superar la presunción normativa contra la intervención penal que sienta el principio de última ratio".

69. NIETO MARTÍN, Adán. Introducción. ARROYO ZAPATERO, Luis y NIETO MARTíN, Adán. El Derecho penal económico en la era Compliance. Valencia: Tirant lo Blanch, 2013, pp. 15-16.

70. En el caso de la Legislación peruana, basta con leer la Exposición de Motivos de la norma para darnos cuenta que el legislador sostiene como segundo elemento de la responsabilidad "administrativa" de la persona jurídica, la "culpabilidad por defecto de organización" de la persona jurídica, sosteniendo textualmente que: "se exige la implementación efectiva de un programa de prevención o cumplimiento, en caso esto no ocurra este elemento de habría configurado". La Exposición de Motivos se puede ver en: <http://www.congreso.gob.pe/Docs/comisiones2016/ConstitucionReglamento/files/dl_1352_(1).pdf>.

71. En la doctrina penal hay posiciones contrarias y sumamente respetables. Por ejemplo, hay quienes ubican al Compliance penal dentro del injusto de la persona jurídica; por todos, Vid. HEINE, Günter. Modelos de responsabilidad jurídico (penal) originaria en la empresa. HEINE, Günter; LAMPE, Ernst Joachim; LAUFER, William S.; GÓMEZ-JARA DIEZ, Carlos y STRUDLER, Alan. Modelos de responsabilidad penal de las personas jurídicas. Propuestas globales contemporáneas. Lima: Ara Editores, , 2012, p. 47, para quien "el punto cardinal del injusto reside en el defectuoso management de riesgos". Hay otros quienes ubican al Compliance penal dentro de la teoría de la imputación objetiva de las personas jurídicas; por todos, Vid. GARCÍA CAVERO, Percy. Criminal Compliance. En especial al Compliance anticorrupción y antilavado de activos. Lima: Instituto Pacífico, 2017, pp. 122-123, para quien “La empresa será competente por el riesgo prohibido cuando sus prácticas, procedimientos internos o estructura favorecen o no dificultan la realización de conductas lesivas por parte de sus miembros individuales. En este punto es posible rentabilizar la figura del criminal Compliance. Si bien las empresas no están obligadas a implementar un programa de cumplimiento respecto de los riesgos penales, si ellas deciden hacerlo, desde la lógica de la autorregulación empresarial, cabrá evaluar el programa de cumplimiento penal adoptado al momento de determinar la relevancia objetiva de su organización, pues la incorporación del criminal Compliance hace que el riesgo de que, pese a todo, el miembro individual pueda cometer un delito en el marco de la organización, sea calificado 
pende del modelo de responsabilidad que se siga. En el sistema vicarial o de heteroresponsabilidad no es que los programas de cumplimiento carezcan de sentido, lo tienen, su función es evitar que se realicen delitos en el seno de la persona jurídica que pueden dar lugar a responsabilidad penal. Lo que ocurre es que una vez que el delito aparece carece de relevancia para la defensa penal de la entidad. Las cosas son distintas en el modelo de responsabilidad propia o de culpabilidad de empresa. Aquí tener una buena organización preventiva es la clave para decidir el sí y el cuándo de la responsabilidad de la persona jurídica ${ }^{69}$.

En este orden de ideas, podemos afirmar que el valor que una legislación otorgue al Compliance penal, es decir, si atenúa o exime de responsabilidad penal/administrativa a la persona jurídica, nos permite obtener mayores elementos para interpretar la legislación y de esta manera poder identificar cuál es el sistema de imputación de responsabilidad acogido por dicha legislación.

El valor que las legislaciones italiana, peruana y española otorgaran al Compliance penal es determinante para saber cuál es el sistema de imputación de responsabilidad penal/administrativa regulado. Si en dichas legislaciones le otorgan al Compliance penal un valor de atenuante de la responsabilidad, podríamos

en relación con la empresa como un riesgo permitido o tolerado". Por último, hay quienes ubican al Compliance penal dentro de la estructura de la acción típica de la persona jurídica, Vid. BAJO FERNÁNDEZ, Miguel. Vigencia de la RPPJ en el Derecho sancionador español. BAJO FERNÁNDEZ, Miguel; GÓMEZ-JARA DIEZ, Carlos y FEIJOO SÁNCHEZ, Bernardo José. Tratado de responsabilidad penal de las personas jurídicas. Segunda Edición. Navarra: Editorial Aranzadi, 2016, p. 43, para quien "La existencia de estos programas o códigos de conducta, obligatorios para todos los miembros de la entidad, en las normas extrapenales y hoy en el propio art. 31 bis, determinan la exclusión de la acción o son causa de atipicidad de la conducta de la persona jurídica".

72. Sobre ello, Vid. GÓMEZ TOMILLO, Manuel. Introducción a la responsabilidad penal de las Personas Jurídicas. Segunda Edición, Aranzadi, 2015, pp. 134-150, quien sostiene "la culpabilidad implicaría un juicio de censura que se formula frente a una persona jurídica porque ha omitido la adopción de las medidas que le son exigibles para garantizar el desarrollo ordenado y no infractor de la actividad relativa al hecho de la empresa. Como en el caso de las personas físicas, la culpabilidad de las entidades colectivas implicaría un complejo juicio valorativo que requiere la ponderación de numerosas cuestiones por parte del juez. Estos datos a tener en cuenta son múltiples, por lo que tan solo puedo considerar alguno de los más importantes, sin que pueda aspirar a agotar la cuestión la existencia o ausencia de un programa de cumplimiento (...)" (p.135).

73. SEMINARA, Sergio. Compliance y Derecho penal: La experiencia italiana. MIR PUIG, Santiago; CORCOY BIDASOLO, Mirentxu y GÓMEZ MARTíN, Víctor [Directores]. Responsabilidad de la empresa y Compliance. Programas de prevención, detección y reacción penal. Buenos Aires: Editorial B de F, 2014, p. 132, quien sostiene "como se puede ver la responsabilidad del ente gira en torno a la omisión de modelos organizativos: en este sentido, la construcción de los Compliance programs como fundamento de la imputación subjetiva cumple una lógica de garantía una vez superado el versari in re illicita".

74. FOFFANI, Luigi. La nueva responsabilidad (ipenal?) de las personas jurídicas en Italia. Dogmática penal de Derecho penal económico y Política criminal. Libro homenaje a Klaus Tiedemann. URQUIZO OLAECHEA, José;ABANTO VÁSQUEZ, Manuel y SALAZAR SÁNCHEZ, Nelson [Coord.]. Lima: Fondo Editorial de la Universidad de San Martín de Porres, 2011, p. 120, para quien “la imputación subjetiva -el aspecto más original del nuevo sistema- se fundamenta en un complejo mecanismo inspirado en el sistema norteamericano de los Compliance programs, sobre la base de los cuales el legislador ha pretendido expresamente dar vida a una inédita forma de culpabilidad de la persona jurídica. De tal forma que la culpabilidad supone que la empresa no haya adoptado o no haya implementado correctamente un modelo de organización y gestión idóneo para prevenir la realización de delitos correspondientes al tipo cometido en el caso concreto".

75. GÓMEZ-JARA DIEZ, Carlos. Fundamentos de la responsabilidad penal de las personas jurídicas. BAJO FERNÁNDEZ, Miguel; GÓMEZ-JARA DIEZ, Carlos y FEIJOO SÁNCHEZ, Bernardo José. Tratado de responsabilidad penal de las personas jurídicas. Segunda Edición. Navarra: Editorial Aranzadi, 2016, p. 107, para quien “las concepciones modernas 
afirmar prima facie que se acoge un sistema de imputación vicarial. Sin embargo, el principal valor otorgado al Compliance penal en dichas legislaciones es que sirven para eximir de responsabilidad penal/administrativa a las personas jurídicas, aunque también se establece que pueden servir de atenuantes cuando son adoptados parcialmente o ex post a la comisión del delito.

En efecto, en dichas legislaciones se establecen que la persona jurídica quedará exenta de responsabilidad penal/administrativa si ex ante a la comisión del delito se implementó en la persona jurídica un Compliance penal. No está demás señalar que este Compliance penal debe ser adecuado a la naturaleza del delito cometi- do, de modo que permita prevenirlo o reducir significativamente el riesgo de su comisión.

Así, el Compliance penal juega un rol fundamental en la atribución de responsabilidad penal/ administrativa de las personas jurídicas, siendo que el valor en dichas legislaciones se le otorga ${ }^{70}$, permiten sostener que recogen un sistema de imputación de "culpabilidad de empresa"71.

En el mismo orden de ideas, en la doctrina penal hay autores como Gómez Tomillo ${ }^{72}$, Semina$\mathrm{ra}^{73}$, Foffani ${ }^{74}$ y Gómez-Jara Diez ${ }^{75}$ que ubican al Compliance penal dentro de la estructura de la culpabilidad de las personas jurídicas, en donde la adopción de un Compliance eficaz y correctamente implementado excluye la culpabilidad ${ }^{76}$.

de la culpabilidad en la persona física relacionan este concepto con el de fidelidad al derecho o disposición jurídica que le es exigible a un ciudadano en democracia. Sin poder entrar aquí en mayores detalles, el equivalente funcional en el ámbito de la persona jurídica es una defectuosa cultura de Compliance. Desde esta perspectiva, la circunstancia de que las organizaciones empresariales puedan generar una cultura empresarial de fidelidad o infidelidad al Derecho o expresado de otra manera, de cumplimiento o incumplimiento de la legalidad, constituye la base de su culpabilidad. Cuando no tienen una adecuada cultura de Compliance la persona jurídica está generando una cultura empresarial de incumplimiento de la legalidad".

76. Gómez Tomillo, Manuel. Introducción a la responsabilidad penal de las Personas Jurídicas. Segunda Edición. Navarra: Aranzadi, 2015, p. 144. 